CUPAUAM 23, 1996, pp. 244-259

\title{
EL CAPITEL CORINTIZANTE Y SU PRESENCIA EN UN CONTEXTO DEL YACIMIENTO HISPANORROMANO DE VALERIA (CUENCA)
}

JORGE CONDE LÓPEZ

\section{Resumen}

El capitel corintizante es una variante del capitel romano corintio normal que, sistematizado por $\mathrm{K}$. Ronczewski, configura uno de los elementos característicos de la decoración arquitectónica de Roma. En el yacimiento hispanorromano de Valeria (Cuenca) su presencia se constata en un grupo de piezas definido estilistica y cronologicamente, con una asignación contextual concreta. El grupo, formado por cuatro capiteles, algunos fragmentos y otros elementos decorativos, es atribuible cronológicamente a la época adrianea, momento para el que hasta ahora existía un vacio en el entramado del yacimiento, pudiendo formar parte de la decoración interior del edificio denominado Exedra, situado en el lado oeste del foro de la ciudad, y configurando un programa ornamental específico al servicio de la utilidad de dicha estructura arquitectónica.

En memoria de Antonio y Fernando

En nuestro planteamiento, el objeto de nuestro estudio se centra en algunos de los aspectos de la arquitectura antigua - e igualmente del urbanismo- cuyo carácter es factor de civilización y comunicación humana, por lo que primero será preciso realizar ciertas puntualizaciones generales referidas a aquellos conceptos que rigen su organización espacial y visual, conceptos que de alguna manera están aglutinados en la idea de orden arquitectóni$\mathrm{co}^{1}$.

' El significado específico de este término no se concreta hasta el Renacimiento. Vitruvio -De Arcb IV- utiliza mores, symmetriae y otros. 
Así, es fundamental ver cómo a lo largo de la Antigüedad la evolución de estos aspectos de la arquitectura se definirá, de modo general, a través de un proceso de progresiva ocultación de las estructuras que corre parejo a un desarrollo de los aspectos técnicos. De tal modo que en la desaparición de las primeras como formas de soporte visibles estará el origen del carácter de lo visible en la arquitectura clásica. La tradición tecnológica incide así no solo estructuralmente, sino también en el lenguaje formal que se manifiesta en el valor del ornamento; además, la función arquitectónica va a adquirir un valor importante en el desarrollo de las formas, lo cual Vitruvio asumió plenamente.

Y es ahora, además, cuando se va a configurar definitivamente la noción de arquitectura pública, a la que se unirá, ya inseparablemente, la comunicación artística como vehículo cultural en todas sus formas, disponiéndose un modo propio de monumentalidad, un lenguaje, en definitiva, con sus reglas propias -la forma como propósito de la arquitectura-, el cual conseguirá un desarrollo sin precedentes en el mundo romano. Sobre todo en su concepto de lo oficial, si bien con interacciones interesantes en distintos grados con la arquitectura privada.

Comprendemos de este modo cómo uno de los componentes esenciales de lo visible en arquitectura -al lado de aquel otro espacial o geométrico- es el ornamento. La función primordial de éste es la de dignificar el objeto y organizar el espacio en el mismo a través de los motivos y de su disposición, siempre en relación con el trazado general y adecuándose al mismo. Sin olvidar tampoco otro elemento de gran influencia como es el significado de la materia y el color -uso de material marmóreo, revestimientos de igual materia para ocultación de mamposterías de opus caementicium, estucos, enlucidos, pintura, etc.

De tal modo se puede señalar que el cometido del ornamento, aunque no terminantemente primordial, es la manifestación precisa de los factores valorativos de la comunicación artística y, concretamente, arquitectónica. Comunicación, ya lo hemos visto, sin duda regida por una sintaxis y cuyos elementos de relación se incluirían en sistemas ornamentales con determinados valores dados que variarían según la organización o programa del mismo. La percepción variará según lo repetitivo de la composición o el grado de libertad de la misma, y sus estructuras de organización lo harán respondiendo a la estructuración, que distinguirá los conceptos de interior o exterior, fachada o lateral, etc ${ }^{2}$.

Es por todo esto que en el análisis de las piezas -a nosotros llegan hoy tanto estructuras como piezas arquitectónicas dispersas, formando éstas segundas el conjunto más numeroso y del que se obtendrá información fundamental para una interpretación global válida, sin que tengan por qué estar asociadas necesariamente a las primeras-, y dado que la pérdida de contextos arqueológicos puede transformar el carácter del objeto de estudio de un modo decisivo, deben seguirse criterios amplios, considerando unas presumibles relaciones de decoración, escultura, arquitectura y otros factores, así como su función en la decoración general, y el cometido de los distintos artífices que intervienen en la materialización arquitectónica y sus grados de profesionalidad (ADAM, 1983, 22 y ss.; Id., 1984, 20 y ss.).

\footnotetext{
${ }_{2}^{2}$ Para toda esta primera parte de la disertación seguimos el trabajo de Javier Gimeno Pascual (1990, 22 y ss.)
} 
Estas líneas que hasta ahora nos ocupaban sirven para comprender mejor y poder presentar, de modo breve, una pequeña parte de aquellos disiecta membra que han dado a conocer las sucesivas excavaciones sistemáticas llevadas a cabo en el yacimiento hispanorromano de Valeria (Cuenca) -actualmente dirigidas por el doctor Fuentes Domínguez- definiéndose ya, y a priori de este estudio, como un conjunto homogéneo arquitectónico-decorativo, incluso programático, acotado estilística y cronológicamente dentro de la globalidad de los elementos del catálogo general, por su procedencia dentro de la trama arqueológica y topográfica del solar valeriense, y atribuibles a un contexto estructural concreto: un conjunto de capiteles corintizantes y otras piezas asociadas.

En el catálogo y estudio actualmente en curso para el Yacimiento se incluyen, como criterio general, todos aquellos objetos que tienen una función ornamental o decorativa en la arquitectura. De manera que se recogen elementos extremadamente diversificados, tanto aquellos que tienen una correspondencia con estructuras conocidas, indudablemente los más escasos, como los que no. En principio tal criterio general nos lleva, en la organización de las piezas, a seguir la definición funcional de los elementos de la arquitectura clásica, si bien para su agrupación los mismos se clasifican siguiendo el tipo de trabajo que cada uno requiere, de tal modo que se consideran dos apartados teóricos: aquellos elementos moldurados, y aquellos otros esculturados.

Refiriéndonos a estos últimos, que son los que nos ocupan, es obvia la presencia en ellos del motivo decorativo, por lo que para la descripción de los mismos nos basaremos en general en el motivo, lo que nos va a permitir establecer con bastante precisión vinculaciones, ya que motivos realizados con determinadas técnicas o siguiendo modelos determinados son inherentes a aplicaciones concretas.

En el yacimiento de Valeria el conjunto de las piezas documentadas como capiteles es uno de los más importantes -tanto por su número como a la hora de aportarnos informacióny, dentro de él, el grupo formado por los capiteles corintios y sus derivados. Por tanto y al margen de aquellos otros capiteles, o fragmentos de los mișmos, toscanos, dóricos o compuestos que han visto la luz en la excavación conquense, es el capitel "de acantos" el que de un modo más profuso parece que acompañó la monumentalización de este Municipium $^{3}$ de la Meseta Sur. Y denominamos de este modo a estos capiteles porque su estructuración decorativa se produce en torno a este elemento vegetal: el acanto, como factor fundamental. De modo que junto al conocido como capitel corintio normal ${ }^{4}$ o canónico, que nos fue definido por Vitruvio, existe una importante diversidad tipológica del capitel de acantos, derivada en principio de aquél, según se produzca en él la presencia o determinada combinación de los diferentes elementos o formas específicas, aunque contando siempre con la presencia de la hoja de acanto como elemento básico. Y es el capitel corintizante, que aquí nos ocupa, una de esas formas de capiteles con variantes derivadas del corintio y no asimilable en ninguno de los tipos canónicos.

'Este es el status juridico-administrativo de Valeria, que más dudosamente sería colonia; disfrutó además. como la mayoria de las ciudades de la zona, de Derecho Latino viejo, tal y como lo recogen GézA ALFOLDY (1987, 85 y ss.) y ÁvGel. FLENTES (1993, 167 y ss.).

- Término acuñado por Heilmeyer (1970). 
El capitel corintizante, también denominado de volutas vegetales, fue individualizado y sistematizado por K. Ronczewskisen 1923 y se caracteriza por una verdadera explosión de elementos vegetales, comunes y específicos para todos ellos, organizados en esquemas diversos, a menudo fantásticos, típicos del naturalismo romano. Se trata de capiteles que coronaron sobre todo pilastras y lesenas decorativas, ya que estos modelos sustentantes sirven mejor a la decoración y. a la coordinación de los muros, y porque los diferentes ornamentos se componen más fácilmente sobre sus superficies planas, iniciando su desarrollo como elementos esencialmente decorativos ya en época helenística, aunque adquieren mayor importancia en la arquitectura romana, donde en el campo de la escultura decorativa se crearon los esquemas más variados (PEnSABENE, 1973, 212).

La formación de los más importantes tipos de estos capiteles se produce desde la época augustea hasta el período flavio. Pero será sobre todo en época imperial cuando se produzca su difusión general. Conocemos ejemplares pompeyanos del primer tercio del siglo I d.C. que ya presentan estas peculiares variantes sobre el corintio normal, para continuar en lo restante del siglo primero y a lo largo del siglo II sin modificaciones destacables, excepto algunas variaciones decorativas de época adrianea. Desde fines de este siglo, y ya a lo largo del III y sucesivos, su uso va decayendo, mostrándose en realizaciones cada vez más esquemáticas (Pensabene, 1973, 219).

Estas piezas mantienen el esquema general de ábaco y kalathos, presentando éste una o dos coronas de hojas de acanto. La frecuente presencia de una única corona de hojas, desde la que en todo caso partirán otras angulares que ascenderán verticalmente, es lo que va a favorecer el desarrollo de los característicos motivos vegetales que completarán el centro del kalathos. Respecto a la naturaleza de las hojas de acanto, es habitual la alternancia de éstas con otros tipos, como las denominadas hojas de agua o las palmetas; por lo que respecta al acanto, además del típicamente romano característico del corintio canónico, se muestra cierta preferencia por variantes "acantizantes" del mismo, con foliolos de perfiles diversos, sin una correspondencia con la realidad del mundo vegetal, lo que las confiere aspectos muy diferentes. Las hojas situadas en los ángulos del kalatbos, aquellas de la segunda si tienen dos coronas de hojas, serán las que al enrollar sus extremos formen sus características volutas vegetales, que muchas veces sobresalen alejándose del kalatbos para sostener los ángulos del ábaco, restándole fragilidad (PENSABENE, 1973, 219); dichas volutas están modeladas del mismo modo que las hojas angulares, apareciendo articuladas en foliolos, y a veces conteniendo la pequeña espiral terminal una roseta en su interior.

Tales motivos vegetales que se desarrollan para ocupar el espacio central libre del kalathos, sin otra función que la puramente ornamental y no estructural como en el capitel corintio canónico, son, siguiendo la tipología establecida por Ronczewski, fundamentalmente tres: de lira, doble "S" y cáliz central, pudiendo existir abundantes variantes sobre estos esquemas por la combinación de sus diversos elementos, para lo que resulta de gran interés

${ }^{5}$ La obra de Roxczewski (1923) es fundamental para la comprensión de las variantes del capitel corintio al realizar su primera y exhaustiva sistematización -esquemas decorativos A-F-, y de especial interés para conocer el origen de los elementos y esquemas decorativos que los caracterizan. 
el reciente estudio de Ulrich-Walter Gans sobre las piezas italianas y de las provincias del noroeste (GANS, 1992).

En cualquiera de los casos, todos ellos ofrecen una diversidad de soluciones e interpretaciones de motivos que proporcionan un campo amplio de estudio de sus tipologías. Pero el origen de estos motivos o temas decorativos se remònta a un momento más antiguo: está en las palmetas y espirales, y sus combinaciones, de la cerámica rodia del siglo VII a.C., en las estelas funerarias griegas o, más desarrollados, en la decoración de los vasos del siglo VI a.C. Pero, quienes favorecieron verdaderamente el desarrollo de estas formas decorativas, de la decoración arquitectónica en general, fueron pintores y estucadores: éstos, frente a arquitectos y escultores, toman más libremente decisiones que enriquezcan sus motivos, crean novedades; los motivos arquitectónicos pintados sobre los muros, o los ornamentos pintados sobre formas arquitectónicas, pueden llevar a los arquitectos hacia nuevos modelos (RoNCZEwSKI, 1923, 115-117). En este sentido debió ser determinante para la introducción y divulgación de este tipo de capitel libremente formado la influencia de la pintura mural del II estilo y los estucos decorativos: Villa de Bosco Reale, "La Farnesina", o la Casa de Livia en el Palatino.

Como regla general los capiteles corintizantes se utilizaron en la construcción de pequeñas construcciones y especialmente en ámbitos domésticos: peristilos, pórticos, y para la decoración interior de palacios y edificios públicos y sepulcrales, encontrándose más raramente en arquitectura de templos (RonczewsKI, 1923, 116). Ahora bien, debemos añadir un factor fundamental en su uso: si en una primera fase, quizá de configuración, estos capiteles se aplican con algún sentido monumental, en una fase consecutiva, quizá la que pueda interesarnos, rara vez se relaciona con una funcionalidad arquitectónica, encontrando sobre todo capiteles de pequeño tamaño, meros relieves decorativos sobre sillares, o piezas de revestimiento: lesenas, de desarrollo importante en el siglo II d.C. (Gimeno, 1990, 1070 y ss.).

Por lo que se refiere a la Península Ibérica ${ }^{6}$, la presencia del capitel corintizante se documenta ampliamente, situándose su área de difusión preferentemente en el tercio sur de la Península, sin faltar en otras zonas como Cataluña y la Meseta, aunque en principio con menor representación. En cuanto a su cronología en la Península, es posible que los primeros ejemplares de este tipo de capiteles pudieran fecharse ya en época tardo-republicana y augustea -se trata de ejemplares muy aislados-, aunque el gran núcleo podría situarse cronológicamente a partir de mediado el siglo I d.C. y durante el siglo II d.C. (GuTIÉRREZ, 1983, 75-76); posteriormente, ya desde el siglo III, comienzan un lento declinar para ya solo encontrar algunos ejemplares que muestran la decadencia del tipo y una decoración aquejada de esquematismo y rigidez ya en el siglo IV d.C.

Volviendo de nuevo al ámbito que habíamos acotado arriba, conoceremos ahora en detalle en qué consiste ese conjunto de piezas homogéneo, de cómoda asignación estilística y cronológica, incluido para su estudio en el inventario y catálogo general del yacimiento de

${ }^{6}$ En este ámbito es necesaria la consulta del algunas obras que recogen monográficamente este tipo de capiteles, como el artículo de GtTtérRez BEHEMERID (1983, 73-104), otras de ámbito geográfico general que en alguna de sus partes refieren a los mismos, como las obras de Diaz Martos (1982), y GtTierrez Behemerid (1992), o aquellas otras que estudian ámbitos locales: para Mérida, DE la BarRera (1984) o para Córdoba, MÁrQtez (1993). 
Valeria y que, individualizado, configura un subgrupo por su carácter corintizante. Procedentes todas ellas de la excavación del área oeste del foro de la ciudad, siempre de niveles de destrucción y relleno, se trata de cuatro capiteles, designados en nuestro inventario como $\mathrm{C} 106$, $\mathrm{C} 107, \mathrm{C} 126$ y C127; y otros elementos en estado fragmentario: fragmentos hojas de kalathos $\mathrm{Cf} 78$ y Cf128, tres volutas con número de inventario Cf9, Cf 44 y Cf 47 , dos flores de ábaco Cf50 y Cf74, un extremo vuelto de hoja Cf80, y varios restos de, probablemente, frisos decorados de más difícil definición Fr1 y Fr2.

Sin eludir la atención de las restantes piezas, vamos a centrar lógicamente nuestra atención en los capiteles que presentan la totalidad de los elementos que los caracterizan, y concretamente en C106 y C107 por un imperativo práctico: C126 y C127 permanecen aún semiocultos en los perfiles de los últimos cortes llevados a cabo en la excavación del yacimiento, aunque las partes visibles no ofrecen duda alguna para su atribución.

C106 (figura 1) es un capitel corintizante de pilastra angular o, mejor dicho, se nos presenta como un sillar con un relieve arquitectónico correspondiente a un capitel corintizante de pilastra en dos de sus caras, las cuales aparecen rebajadas respecto de la superficie original restando regularidad a la pieza cúbica. Presenta sin decorar el resto de sus caras. Está rea-

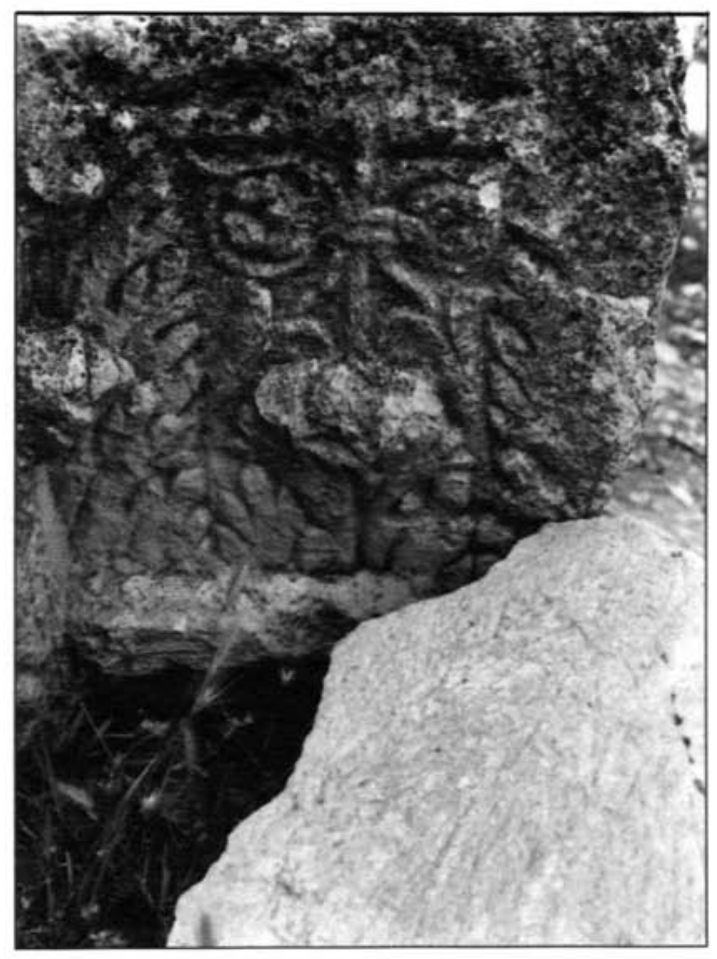

Figura 1. Capitel corintizante C106. 


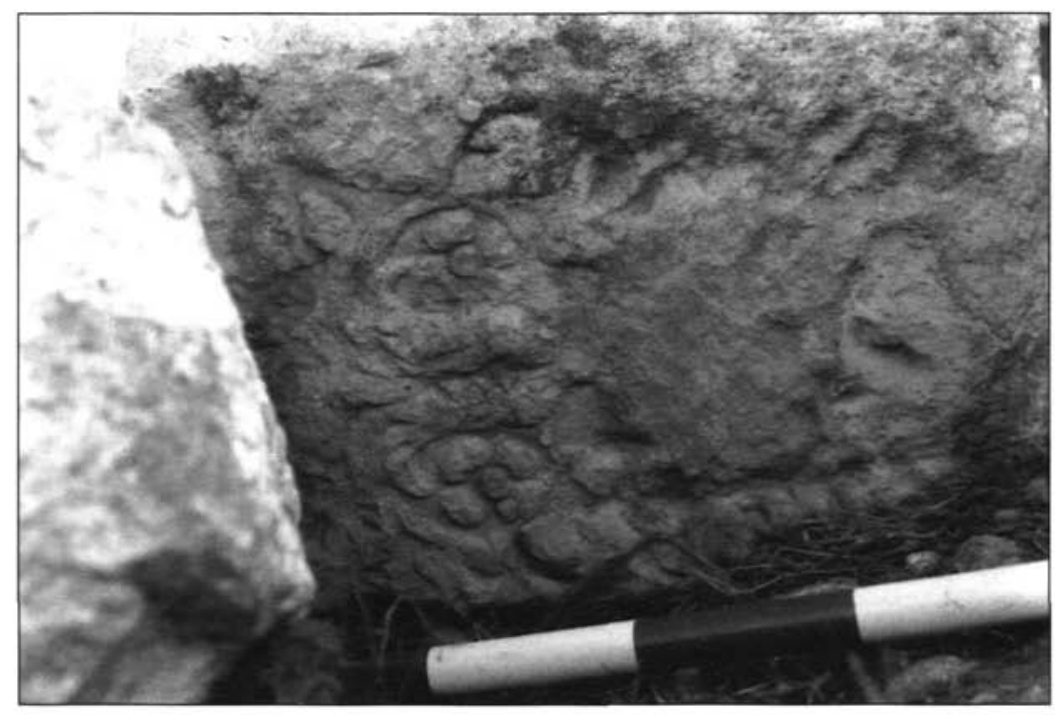

Figura 2. Capitel corintizante C107. Cara 1.

lizado en caliza local, con restos de revestimiento de estuco, y presenta erosión parcial que afecta especialmente al ábaco y salientes. En el centro de su cara superior, un hueco para una grapa de sujeción. Ausencia de trépano.

Medidas del sillar: $\mathrm{h}=52 \mathrm{~cm} ; \mathrm{l}=62 \mathrm{~cm} ; \mathrm{g}=64 \mathrm{~cm}$.

Medidas del capitel: $\mathrm{h}=48 \mathrm{~cm} ; \mathrm{h} 1=22 \mathrm{~cm} ; \mathrm{h} 2=20 \mathrm{~cm} ; \mathrm{hAb}=6 \mathrm{~cm}$.

A pesar de que se trata de un relieve, es decir, que el capitel no desempeña una función tectónica propiamente dicha, la consideración de la pieza es la misma al constituir una decoración arquitectónica y monumental, probablemente de un interior de un edificio. La parte inferior de las caras rebajadas y decoradas muestra un astrágalo liso e indisoluble del capitel. La única corona de hojas presenta alternancia de hojas de acanto y corintizantes; las primeras, de nervio central marcado por una ligera acanaladura y lóbulos planos divididos en cuatro foliolos lisos y redondeados, muy semejante tipológicamente a otros ejemplares procedentes del yacimiento; las otras, aquellas de los laterales y las angulares ascendentes, muestran un perfil más marcado y dentellado, aunque igualmente planas y de realización técnica semejante. Aquellas de desarrollo vertical terminan enrolladas configurando volutas de carácter vegetal con forma de espiral cerrada, que conservan la marca de los lóbulos articulados de igual modo que el resto de la hoja casi hasta su extremo, terminando en un polo semiesférico.

Todo ello enmarca el motivo central que ocupa la superficie libre del kalathos, motivo del tipo C de Ronczewski en forma de lira; esto es: con origen en sendos cálices abiertos, en este caso sostenidos por sus respectivos caulículos -inclinados, largos y lisos- que surgen de entre las hojas de la corona inferior, se desarrollan dos tallos encarados que suben en 
forma de lira para terminar en una espiral cada uno, en cuyo interior dan lugar a rosetas de cuatro pétalos carnosos; las espirales están unidas mediante una cinta doble, y pasa entre ellas un grueso tallo central del que nace la flor de ábaco, perdida.

El origen del motivo es antiguo; formando la pareja de espirales que llamamos lira, pero $\sin$ flores, se encuentra en estelas del V y IV a.C., sobre vasos de figuras rojas o en terracotas itálicas republicanas; será en los últimos tiempos de la República cuando esta lira se trasponga a la superficie de los kalathos en los capiteles de lesena. En los bajorrelieves del Ara Pacis augustea ya se ve este motivo de lira. En su configuración definitiva, a la que Ronczewski ofrece una fecha post quem del 63-79 d. C. (RonczewsKI, 1923, 139-140), lo vamos a encontrar hasta final de época julio-claudia, y su popularidad perdurará en los tiempos del barroco flavio y durante el siglo II hasta la época severiana; después se volverá raro (Pensabene, 1973, 220).

La pieza C107 (fig. 2 y 3) se configura del mismo modo que C106, como sillar con relieve arquitectónico correspondiente a un capitel corintizante de pilastra angular. Igualmente rebajado y labrado en dos de sus caras, el material es idéntica piedra caliza con trazas de estucado, y presenta erosionados sus salientes y ábaco, así como la mitad inferior correspondiente a la corona de hojas. Ausencia de trépano.

Medidas del sillar: $\mathrm{h}=50 \mathrm{~cm} ; \mathrm{l}=54 \mathrm{~cm} ; \mathrm{g}=58 \mathrm{~cm}$.

Medidas del capitel: $\mathrm{h}=48 \mathrm{~cm} ; \mathrm{h} 1=22 \mathrm{~cm}$ aprox.; $\mathrm{h} 2=20 \mathrm{~cm} ; \mathrm{hAb}=6 \mathrm{~cm}$.

Caben las mismas consideraciones que para la pieza anterior funcionalmente. Ahora bien, a diferencia de C106 ahora no hay trazas de existencia del astrágalo. Por lo que se refie-

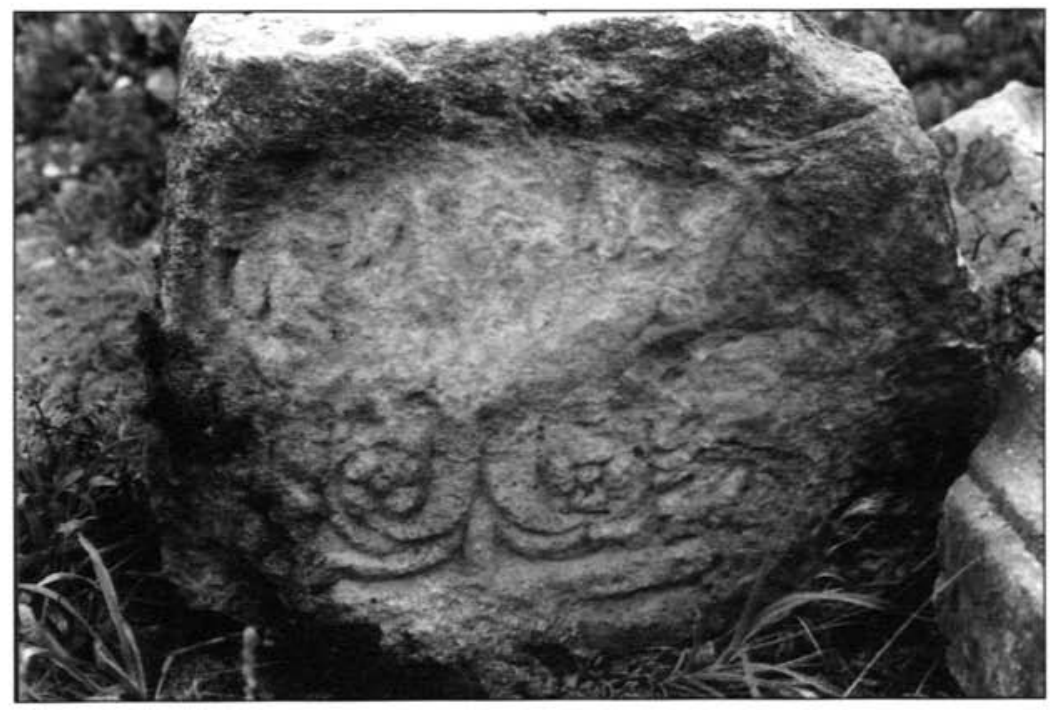

Figura 3. Capitel corintizante C107. Cara 2. 


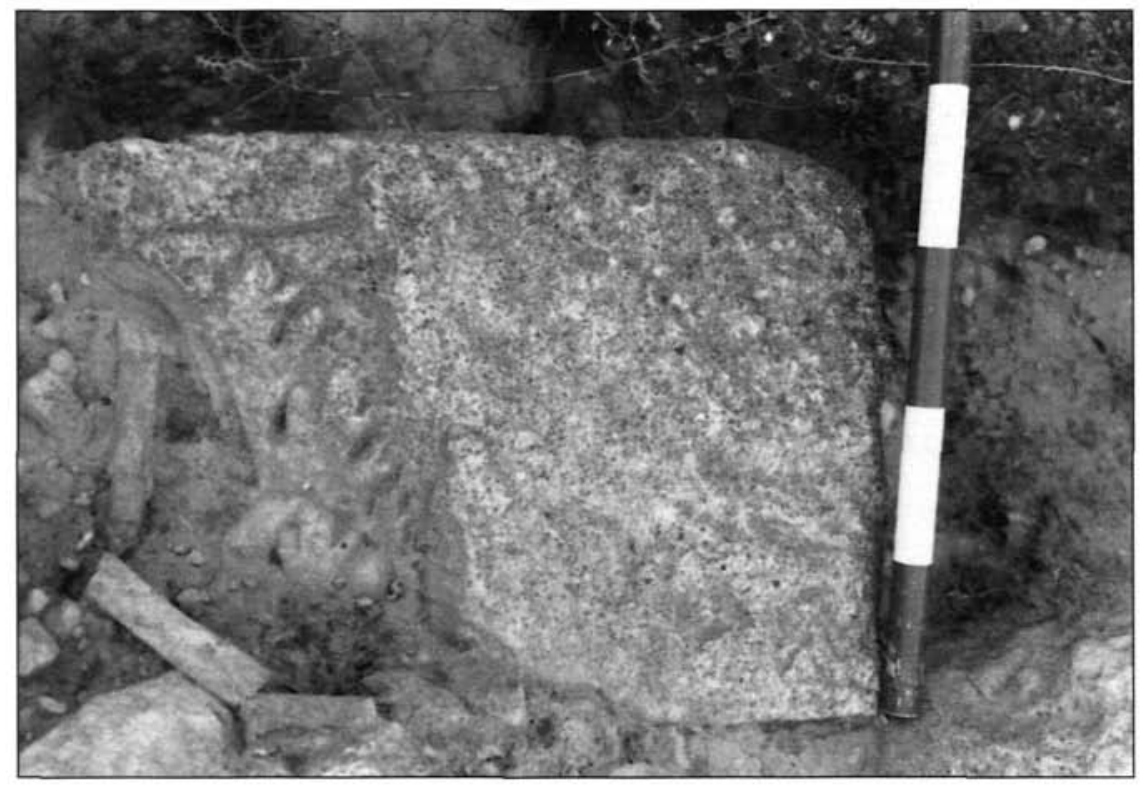

Figura 4. Capitel corintizante $\mathrm{C} 126$ inserto en un perfil.

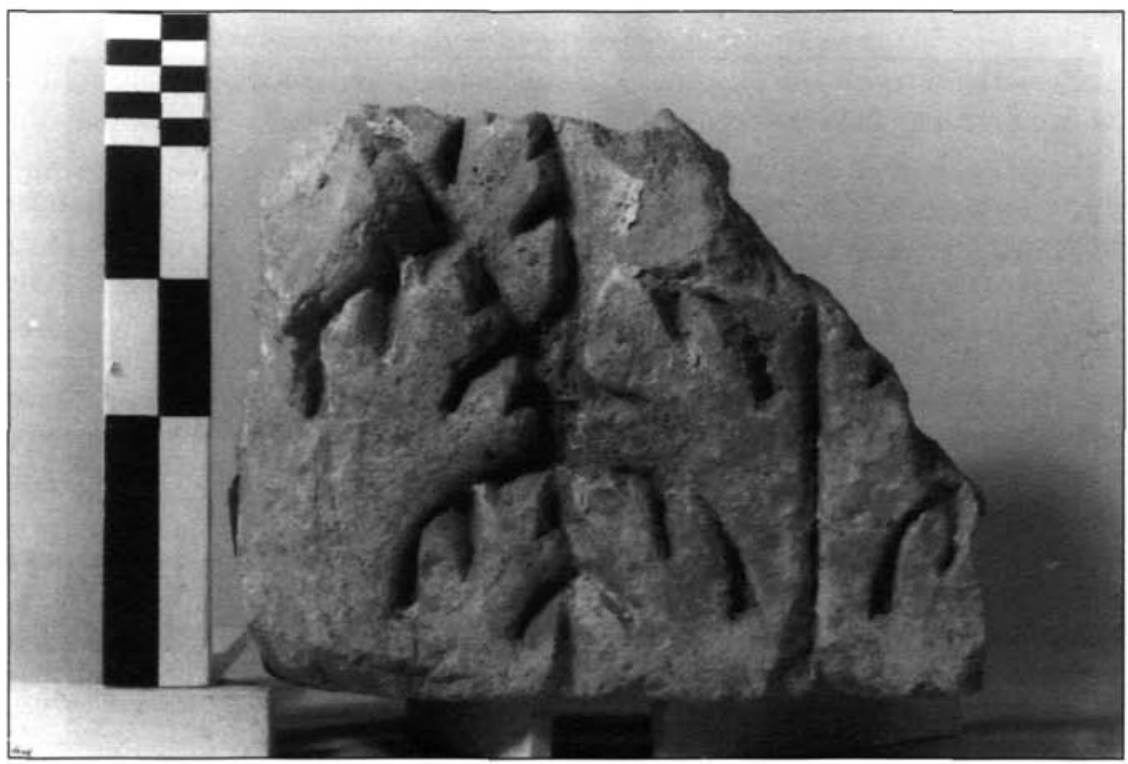

Figura 5. Fragmento de kalatbos del capitel corintizante CF78. 


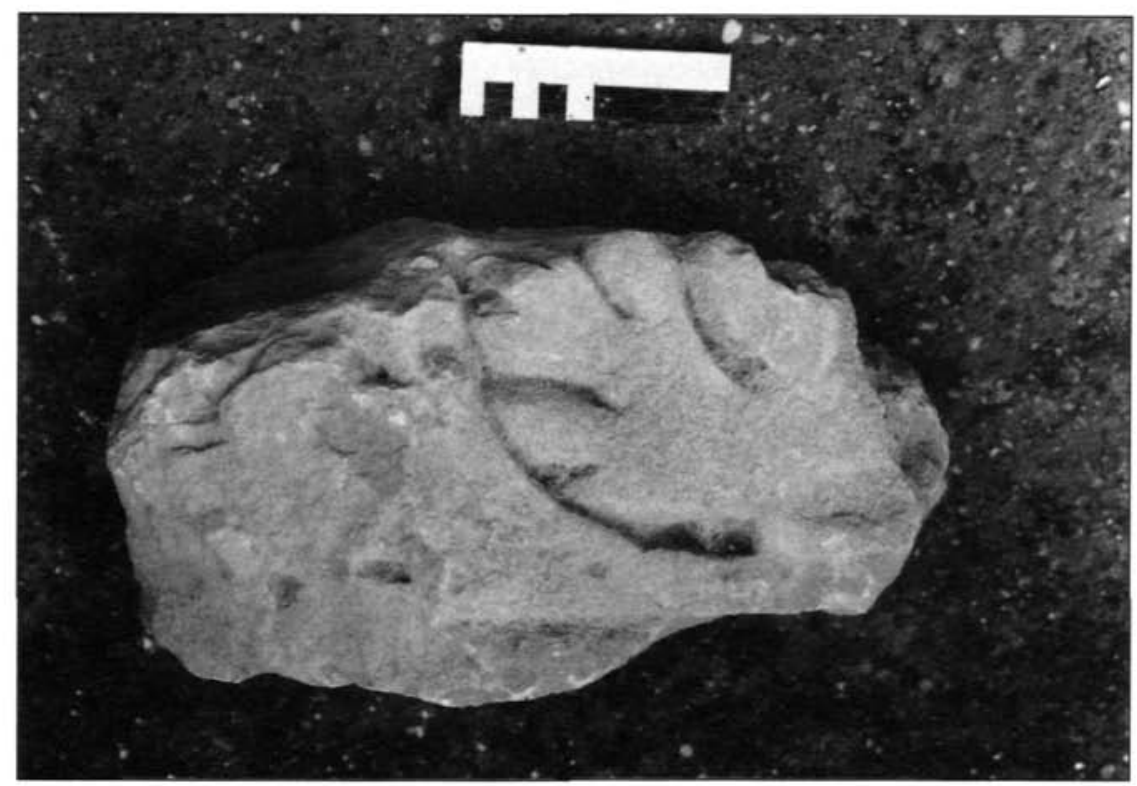

Figura 6. Fragmento de capitel corintizante Cf128.

re a las hojas que lo configuran, cabe suponer que la corona arrasada tendría la misma configuración que el ejemplar anterior, alternando hojas de acanto y acantizantes, y pudiéndose tan solo observar la parte más alta de estas segundas, las angulares, a la altura del arranque de las volutas, que, en todo caso, presentan idéntico trabajo y aspecto que C106.

En cuanto a la decoración central de su kalathos, aunque dañada, podemos observar la parte superior de un motivo de lira tipo C, con igual traza y trabajo, pero con ligeras variantes respecto al anterior: apenas perceptible la parte superior de los cálices abiertos, los tallos ascendentes son más carnosos en el momento de iniciar la espiral, adoptando una forma más vegetal con pequeñas hojitas a partir de las que parte el tallo más estrecho que termina de rodear la roseta final. En su otra cara decorada, el engrosamiento del tallo no presenta las pequeñas muescas que marcan esas hojitas, continuando con igual esquema. No existe la cinta que reúne ambas espirales con el tallo de la flor de ábaco. Son pequeñas variantes sobre el mismo esquema, sin dudas atribuibles a la libertad del artista a la hora de elegir y desarrollar los motivos ornamentales.

En general, ambas presentan un aspecto clásico algo alejado de otras piezas del yacimiento que entregan cierta parte de su valor decorativo al claroscuro del trépano, prefiriendo contornos más blandos y suaves, volúmenes "carnosos", tal vez más "naturales".

Por lo que respecta a los capiteles semienterrados C126 (figura 4) y C127, son pocos los datos que podemos ofrecer dada su difícil accesibilidad, excepto que las dimensiones de los sillares que soportan las decoraciones de las caras del capitel son semejantes a las de los 


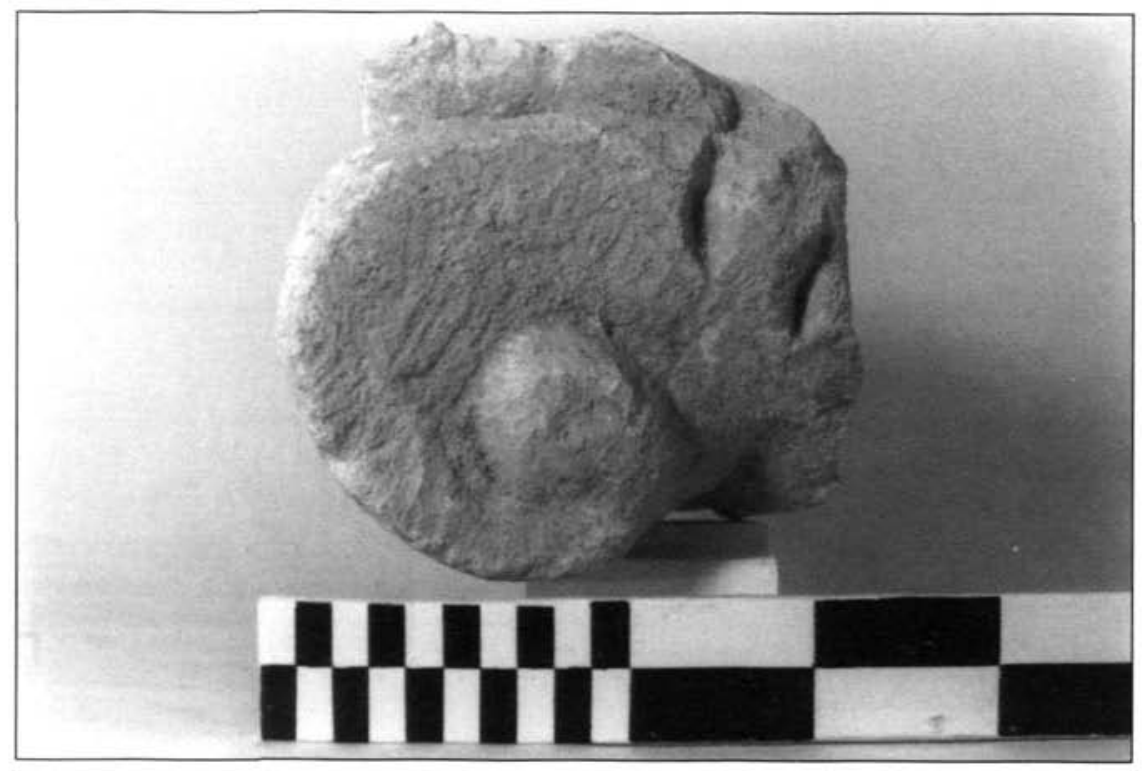

Figura 7. Voluta Cf9.

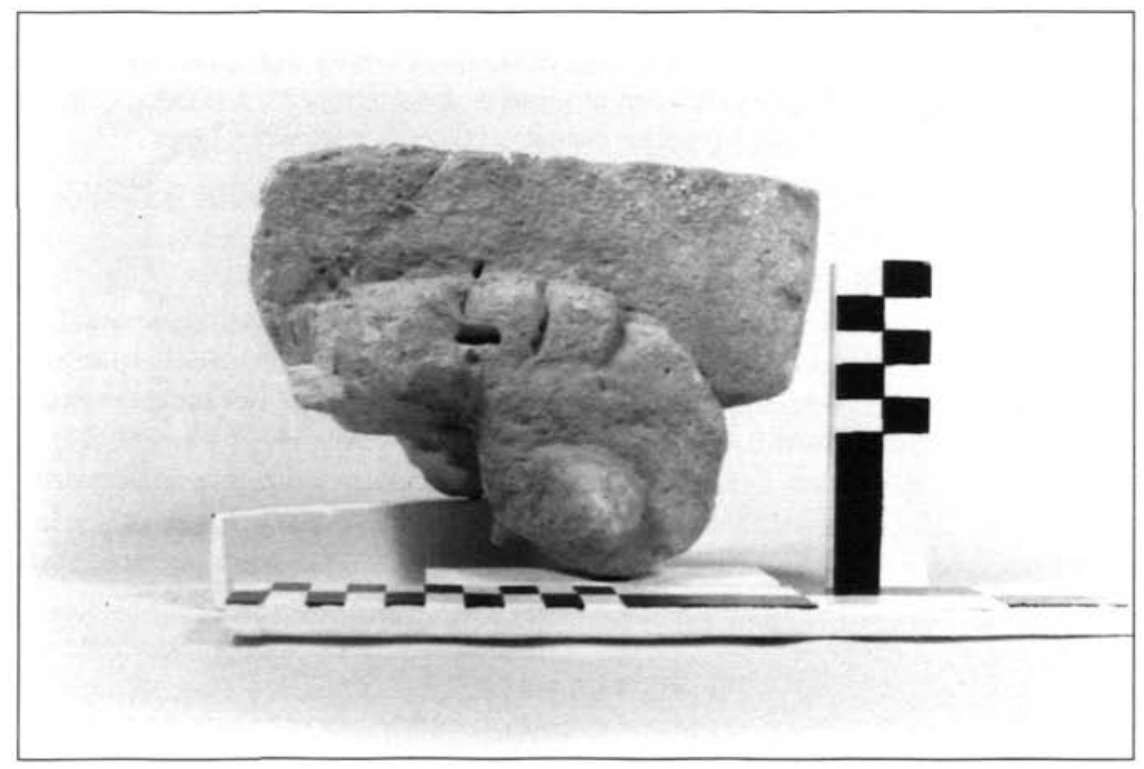

Figura 8. voluta $\mathrm{Cf} 44$. 


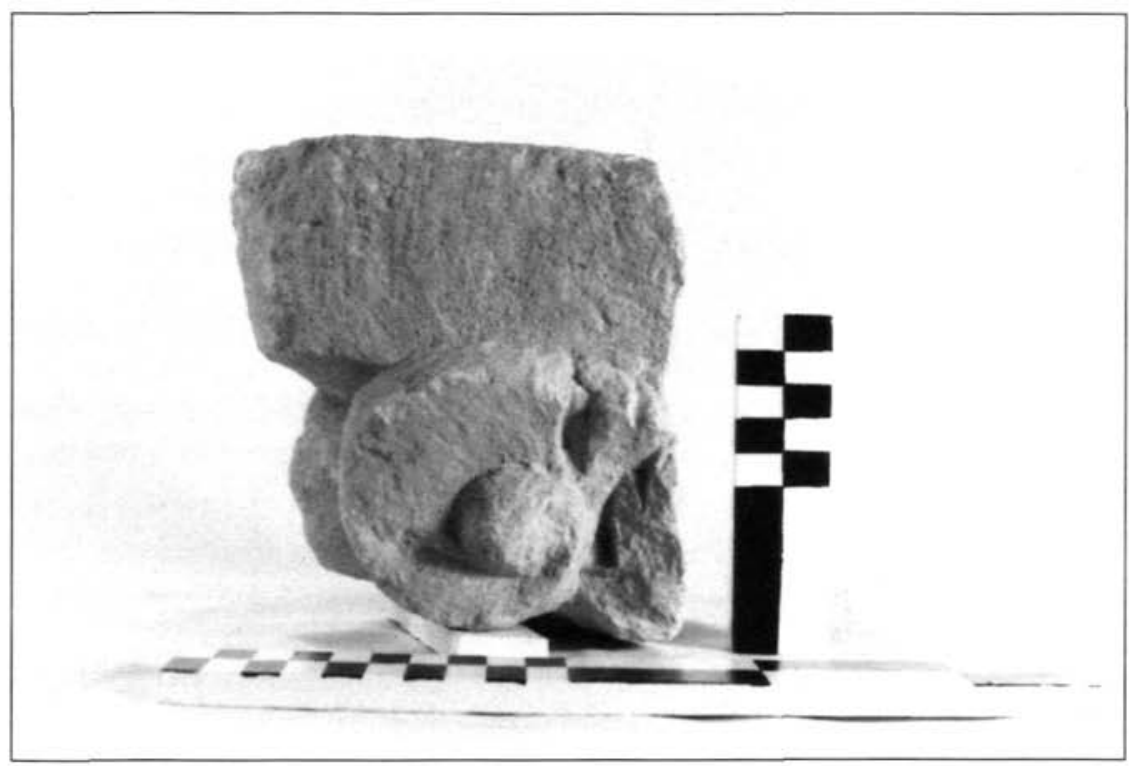

Figura 9. Voluta Cf47.

dos anteriores y que los esquemas y trazas decorativas y, lo que es esencial, sus hojas acantizantes, son análogas. En este mismo sentido abordamos los fragmentos de kalathos denominados Cf78 (figura 5), con parte de la corona de hojas, y Cf128 (figura 6); ambas muestran el mismo tipo de hoja que todas las piezas anteriores, lo cual nos lleva a completar definitivamente la homogeneidad del grupo de capiteles: todos ellos corintizantes y decorados, en la medida en que los elementos fragmentarios permiten apreciarlo, con el motivo decorativo de lira, idéntico tipo de hojas y un modo de elaboración semejante: seguramente todos ellos creados por las mismas manos.

Tal vez pertenecientes a estas mismas piezas, algunos fragmentos acompañaron a las arriba descritas en su localización: las volutas, identificadas como Cf9, Cf44 y Cf47 (figuras 7 , 8 y 9 respectivamente) tienen idénticas características entre sí y que las que aún se conservan en alguno de los capiteles, siendo determinante su carácter vegetal: la espiral se configura con el extremo de las hojas acantizantes angulares, marcándose su articulación en lóbulos, y finalizando en idéntico polo hemiesférico. Lo mismo puede decirse de los elementos Cf80 (figura 10), el extremo vuelto de una hoja acantizante que bien pudiera corresponder a cualquiera de los capiteles anteriores por su tipología y características técnicas, y Cf50 y Cf74 (figura 11), idénticas flores de ábaco $-\mathrm{h}=14 \mathrm{~cm}$ - que contienen en el centro un fruto en forma de pina liso; los pétalos reproducen la articulación y el perfil de los lóbulos de las hojas laterales del kalathos, y en general su realización técnica también es coincidente con el resto de las piezas vistas arriba: acanaladuras ligeras, talla mecánica y volúmenes carnosos, muy semejante al que se observa en los otros elementos vegetales del motivo central y, especialmente, en los pétalos de las rosetas. En cuanto a sus dimensiones, éstas las hacen perfecta- 
mente atribuibles a los capiteles anteriores. Por otro lado, es un tipo de flor de ábaco muy utilizado en el capitel corintizante, como atestiguan numerosos ejemplares de Mérida y Córdoba, o un buen porcentaje de los romanos y ostienses.

Conocidos ya todos los elementos, completos o fragmentarios, que conforman el subgrupo, podemos asegurar su unidad de estilo y técnica, así como su carácter corintizante. Por otra parte, esta unidad ya parecía dada a priori por su procedencia de un contexto común y único dentro del yacimiento: el flanco oeste de la plataforma del foro; y, más concretamente, de la excavación del denominado edificio de la Exedra, que debió levantarse abriendo las puertas de su planta absidal en el centro del lado occidental del pórtico foral, sobre la cubierta de los aljibes, y que debió sufrir una destrucción, al menos parcial, dentro de la mitad inicial del siglo II d.C. (Fuentes, 1993, 179 y ss.). Dato éste de gran interés para una asignación cronológica.

Antes es importante, en el mismo sentido, hacer referencia a sus paralelos con otras piezas conocidas y con asignación cronológica segura, tanto dentro como fuera de la Península. En primer lugar aludimos a los ejemplares ostienses nos. 558 y 559, recogidos por Pensabene en su catálogo que, con idénticos motivos de lira, presentan una realización estilística y técnica muy semejante y que se datan dentro de la primera mitad del siglo II, más bien alrededor del primer tercio del siglo (Pensabene, 1973, p. 139, n. 558 y 559). Lo mismo puede decirse de los dos ejemplares conservados en la Alcazaba de Mérida y estudiados por de la Barrera, nos. 72, con total coincidencia del tipo de hoja, y 73 , en este último el motivo central es una derivación del motivo de lira original, si bien con sus rasgos generales de rea-

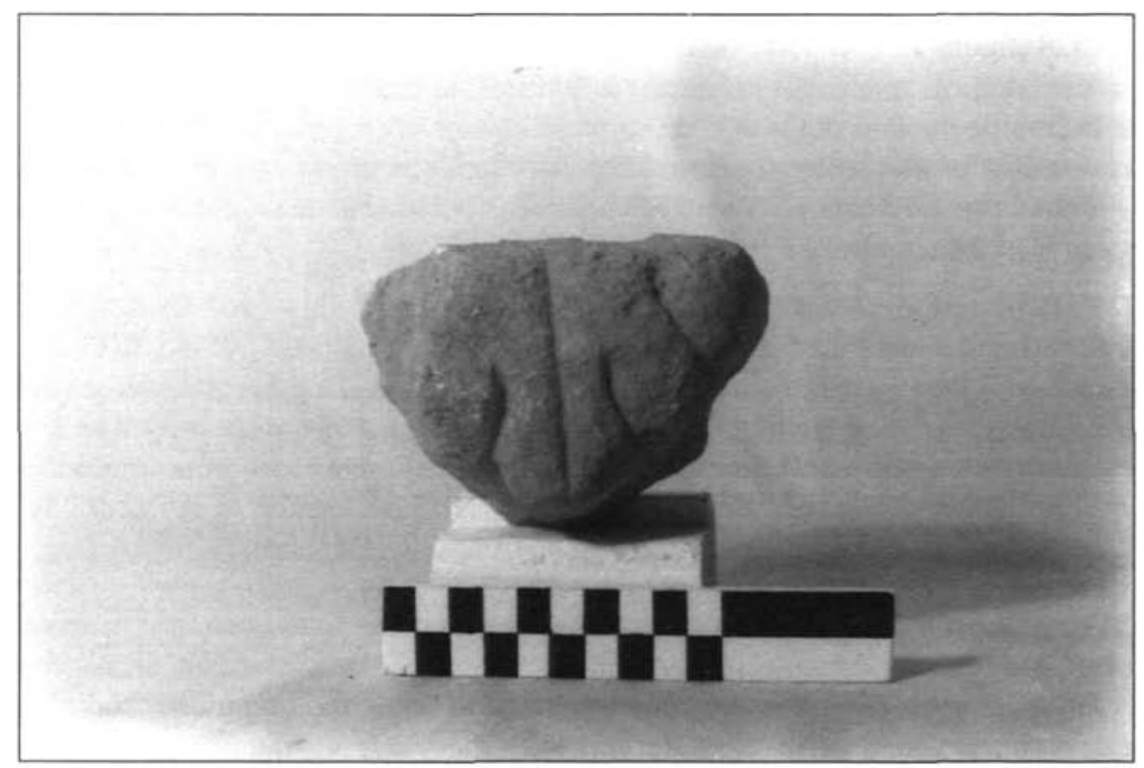

Figura 10. Extremo vuelto de hoja Cf80. 


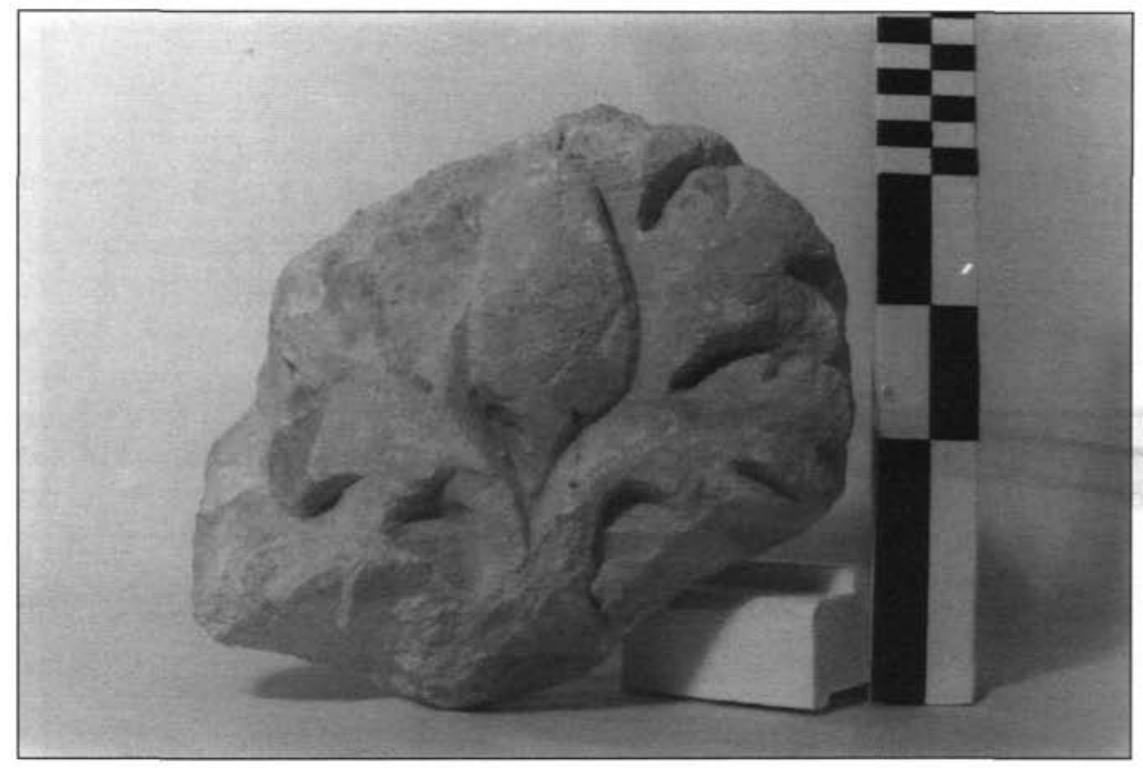

Figura 11. Flor de ábaco Cf50.

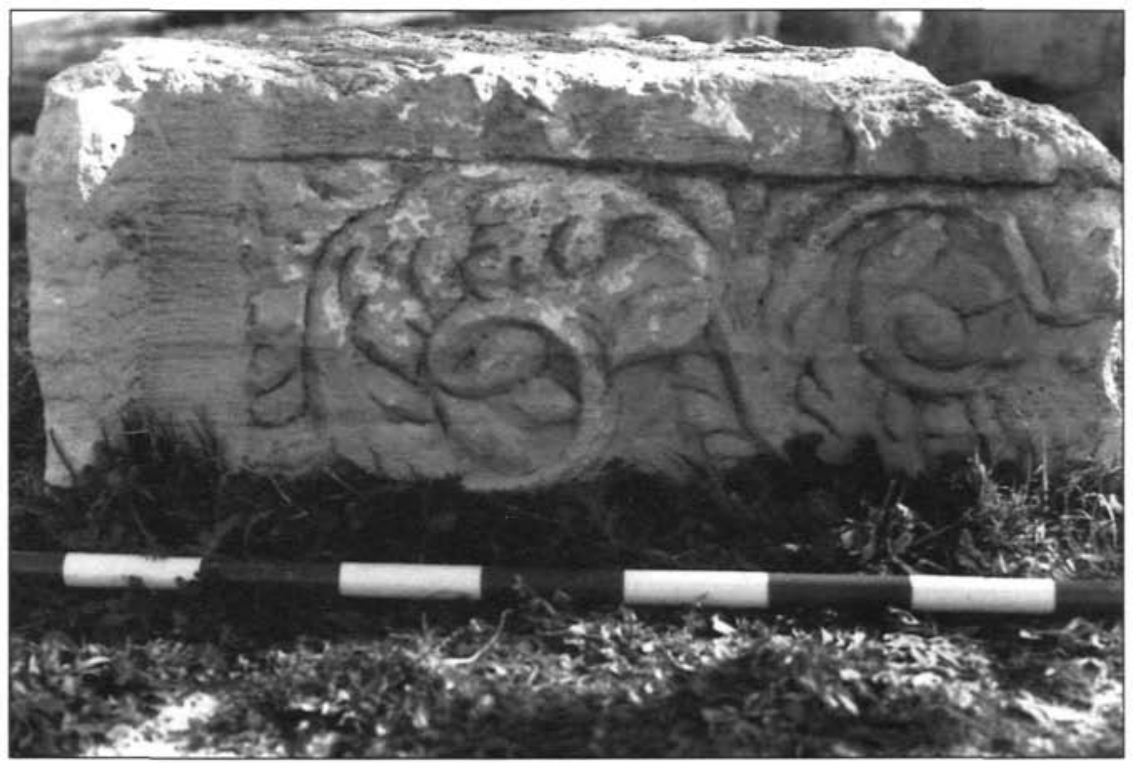

Figura 12. Relieve decorativo Fr1. 


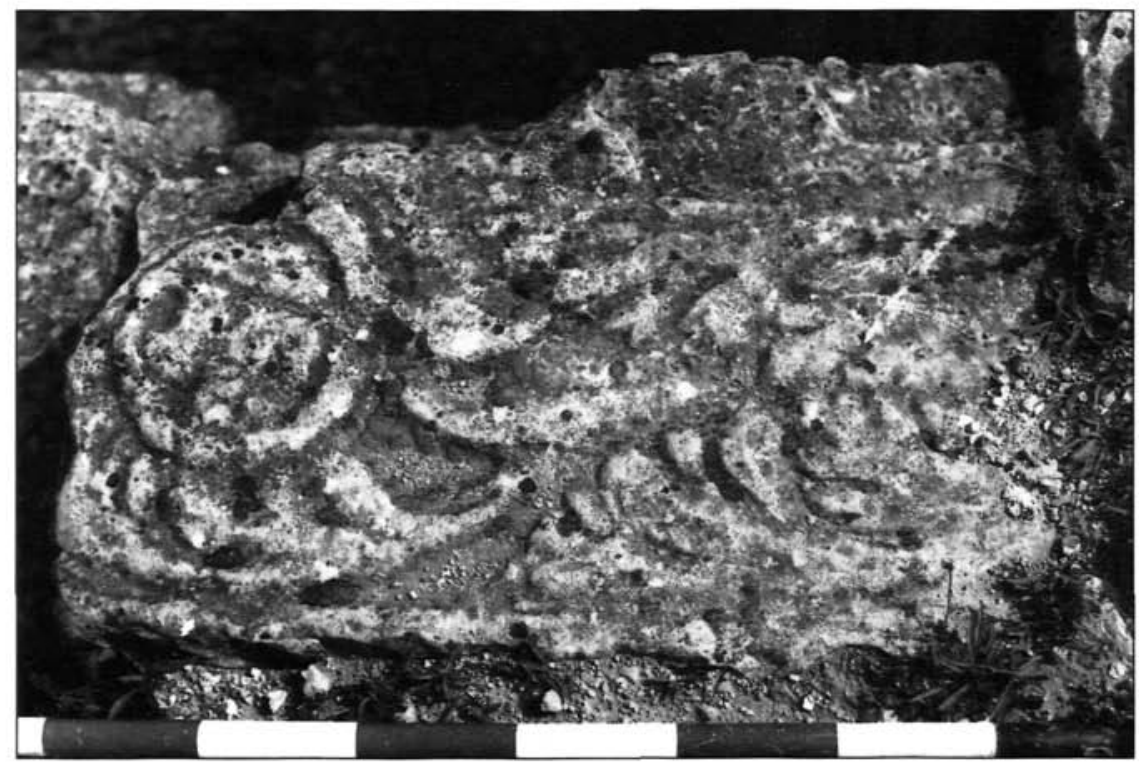

Figura 13. Relieve decorativo Fr2.

lización del todo coincidentes. Ambos fechados en época adrianea (DE LA BARRERA, 1984, 5152, n. 72 y 73). Por último cabe mencionar el estudio que Gutiérrez Behemerid realiza de nuestra pieza C106, a la que atribuye una cronología en la transición entre el siglo I y II d.C., tal vez algo temprana para nuestra concepción (GuTiérrez, 794 y ss., n. 811).

Las fechas del entorno de la primera mitad del siglo II d.C., y con la perspectiva de lo visto más arriba, nos posibilitan realizar una hipótesis de atribución de las piezas dentro del tejido del discurso cronológico-espacial del yacimiento. El doctor Fuentes Domínguez señala que la época trajano-adrianea debió ser un período edilicio dorado, aunque muestre resistencia a ser documentado en extenso en las excavaciones. Hasta inicio del siglo III se mantuvo la refacción y mejoras urbanas; así la realización de la escena del teatro de Segóbriga, o en Valeria, tras la destrucción accidental de los aljibes y parte de la Exedra en la primera mitad del siglo II, la restauración del edificio incluso con un aderezo arquitectónico aun más rico (Fuentes, 1993, 179). Así, no solo la paralelización con otras piezas arquitectónico decorativas nos está concretando una cronología cierta por afinidades estilísticas y ornamentales, sino que observamos una refacción arquitectónica precisamente de la estructura que ocupaba el espacio del que procede el grupo de piezas que estamos estudiando para unas fechas coincidentes con las vistas.

Efectivamente parece que, por la naturaleza de los materiales encontrados, la reconstrucción del edificio de la Exedra se realizó dignificándola ornamentalmente y dotándola de un programa decorativo del todo diferente al resto del yacimiento, tal vez por tratarse de una estructura arquitectónica de una funcionalidad específica y destacada. Asociados a los restos 
ya estudiados arriba aparecen materiales marmóreos -placas de revestimiento- y escultóricos, los relieves decorativos hasta ahora no comentados Fr1 y Fr2 (figuras 12 y 13), configurados por roleos de tallos y hojas acantizantes iguales a los de los capiteles corintizantes, con rastros de estuco, y que tal vez tuvieran función de jambas o dinteles, y pilastras estriadas de esquina y restos de lesenas de dimensiones asociables a las de los capiteles. Son elementos todos ellos que configurarían, junto a los anteriores, todo un sistema ornamental organizador y articulador del espacio interior del edificio, que quedaría revestido de finas placas marmóreas y articulado por las lesenas, con todo un sistema de arquitectura decorativa muy probablemente con aplicaciones pintadas y de enlucidos -mezclas de cal y polvo de mármol destinadas a buscar la imitación del mármol como maquillajes menos nobles-sobre los bloques calizos que soportan los relieves de formas arquitectónicas y decorativos para dotarlo de un valor de comunicación concreto; tal vez, y aunque esto sí que sea una conjetura remota, relacionado con el culto imperial.

Hipótesis que, tal vez, nos ayudan a llenar ese vacío edilicio que se produce a lo largo del siglo II d.C.

\section{BIBLIOGRAFÍA}

ADAM, J.P. (1983): "La recherche des techniques de chantier de l'architecture antique". Le courrier du CNRS 51 suppl., 22 y ss.

ADAM, J.P. (1984): La construction romaine. Materiaux et techniques. París.

ALFÖLDY, G. (1987): Romisches Städtewesen auf der neukastilischen Hochebene: Ein Testfall für die Romanisierung. Heidelberg.

De La Barrera Antón, J.L. (1984): Los capiteles romanos de Mérida. Badajoz.

Díaz Martos, A. (1982): Capiteles corintios romanos de Hispania: estudio-catálogo. Madrid.

Fuentes Domínguez, A. (1993): "Las ciudades romanas de la Meseta Sur". La ciudad hispanorromana. Barcelona. 160 y ss.

GANS, UlRICH-WALTER. (1992): Korinthisierende Kapitelle der römische Kaiserzeit: Schmuckkapitelle in Italien und den nordwestlichen Provinzen. Köln.

GutiérRez BEHEMERID, M.A. (1983): "El capitel corintizante: su difusión en la Península Ibérica". BSAA XLIX. Valladolid.

GutiérRez BeHEMerid, M.A. (1992): Capiteles Romanos de la Península Ibérica. Valladolid.

Gimeno Pascual, J. (1990): Estudios de Arquitectura y Urbanismo en las ciudades romanas del nordeste de Hispania. Madrid.

HEILMEYER, W.D. (1970): Korinthische normalkapitelle: Studien zur geschichte der römischen Architekturdekoration. Heidelberg.

MárQuez, C. (1993): Capiteles romanos de Corduba Colonia Patricia. Córdoba.

Pensabene, P. (1973): Scavi di Ostia. VII. I capitelli. Roma.

RONCZEWSKI, K. (1923): "Variantes des chapiteaux romains". Acta Universitatis Latviensis, VIII, 1923.

Vitruvio. (1960): De Architectura (dai libri I-VIII). Roma. 